\title{
EXTUBAÇÃO PALIATIVA EM UMA UNIDADE DE CUIDADOS PEDIÁTRICOS: PERCEPÇÃO DA EQUIPE MULTIPROFISSIONAL
}

Felipe Leonardo Rigo Hospital Infantil João Paulo II felipeleonardorigo@hotmail.com

Stayse Soares de Almeida Hospital Infantil João Paulo II staysealmeida@gmail.com

\author{
Elizabeth Iracy Alves Leite \\ Hospital João XXIII / FHEMIG \\ bebel.leite@gmail.com
}

\section{RESUMO}

INTRODUÇÃO: A retirada de suporte invasivo, como a ventilação mecânica, constitui uma medida de alívio a dor ao paciente e é frequentemente realizada no momento anterior a morte. Nos casos de limitação terapêutica onde a morte é esperada, a extubação paliativa se torna uma medida de conforto nesse momento. Sua indicação e execução requer equipe multiprofissional, discussão e envolvimento prévio de toda equipe, diálogo, participação familiar e transcende para além das demandas dos cuidados rotineiros. OBJETIVO: Investigar a percepção dos profissionais que vivenciam o processo de extubação paliativa. METODOLOGIA: Estudo qualitativo e exploratório, realizado na unidade de cuidados paliativos pediátricos de um hospital público da rede estadual de saúde de Minas Gerais, em 2020. Estudo aprovado pelo Parecer: n 4.071.373. RESULTADOS: Foram entrevistados II profissionais de saúde. Emergiram 4 categorias temáticas: Conhecimento prévio a acerca da extubação paliativa; Planejamento da conduta; Comunicação entre equipe e compartilhamento do cuidado e Percepção e entendimento sobre o procedimento. Os profissionais relataram maior conhecimento teórico sobre a extubação paliativa porém, trouxeram que compreenderam melhor o procedimento na prática. Algumas classes profissionais não se sentiram incluídas no planejamento assistencial que abrangia conversa prévia com os familiares do paciente e discussão sobre o plano de cuidados. Falhas na comunicação entre os membros da equipe também foram evidenciados por profissionais não médicos. $O$ procedimento foi entendido por todos os profissionais como necessário em virtude do prognóstico clínico da criança. CONCLUSÃO: Faz necessário realizar novas pesquisas relacionados as percepções da equipe multiprofissional frente às estratégias assistenciais em unidades de cuidados paliativos para que as condutas sejam alinhadas e haja maior envolvimento de todos profissionais.

PALAVRAS-CHAVE: Cuidados Paliativos; Pediatria; Extubação 